\title{
Test and analysis of the main crane girder stress and the dynamic characteristics of column
}

\author{
Hongbin Liu ${ }^{1 b}$ Shouqing Liu ${ }^{1 a^{*}}$ \\ ${ }^{1}$ University of Science and Technology Liaoning, Anshan, Liaoning, 114051, China \\ a513590536@qq.com , b binbinliu999@126.com
}

\begin{abstract}
Key word: Crane beam; stress test; dynamic characteristic test;
Abstract: Due to the long construction time of a steel mill, carried on reinforced many times, multiple replacement and an increase in crane, the pillars of the main building now have a larger vibration. Roof damage Serious. Plant leak serious, in order to guarantee the reliability of building structure, needed to carry out the reliability evaluation of the plant, in this paper, the stress and dynamic characteristics of crane beam and column are tested. In order to evaluate the crane beam system better and the column system for more comprehensive, provided reliable basis for strengthening and rebuilding of plant.
\end{abstract}

\section{Engineering survey}

A steel plant was built in 1958,put into operation in 1960, the workshop is made up of three assemble structure. The main span (Д-И), deputy Cross (A1-B1), transition (Д-В1) across three parts. The main span and the sub span are $21 \mathrm{~m}$, the transition span is $6 \mathrm{~m}$. The column distance is $6 \mathrm{~m}$. The retaining structure is made of brick wall. In 1964, the main span roof system is transformed, the original crane of the main span will be a replacement of $75 / 20 \mathrm{t}$ crane. After the replacement of the crane from the weight is still 75/20t,and increasing a new 75/20t crane. The full length of the plant is $266.4 \mathrm{~m}$ (axis length). Wide is $48 \mathrm{~m}$ (axis width), Cornice elevation is $20.15 \mathrm{~m}$, construction area is about $12903 \mathrm{~m}^{2}$. The main span of the workshop, upper and lower column using rectangle or I-shaped reinforced concrete column, the double leg column of reinforced concrete is used in the upper and lower column. Cross shaped steel bracing was adopted for all the support of the columns. The vice and main span are all adopted welding I-shaped steel crane girder. Except forИ/16-18.И/18-20.И/20-22.И/22-24. И/25-27 are 12m, the rest is $6 \mathrm{~m}$. As the main span of the plant to replace the crane, the vibration of the column and factory buildings, such as water leakage, roof panels damaged and other factors affecting the safety of the plant. Therefore, it is necessary to detect and identify the plant, in particular, the stress and dynamic characteristics of the crane beam and the column system is tested to detect and identify the conclusions and suggestions. Can also provide the technical basis for strengthening design of the plant.

\section{Crane beam stress test}

Layout of measurement points. In order to find out the actual stress level in the normal operation of the crane girder, the stress test is chosen typical crane beam to provide the basis for the analysis. The test for the crane load weight is self weight plus lifting weight, the crane weighs 66.5 tons. Among them, the load weights are 66.5 tons. According to the structural characteristics and stress state of crane girder, this testing chooses the crane girder of (27 - 28/Дaxis) which runs frequently to carry on the stress strain test. In the cross section of the crane girder, the strain gauges are pasted in the cross section of the crane beam. The location of each measurement point is shown in Figure 1. 


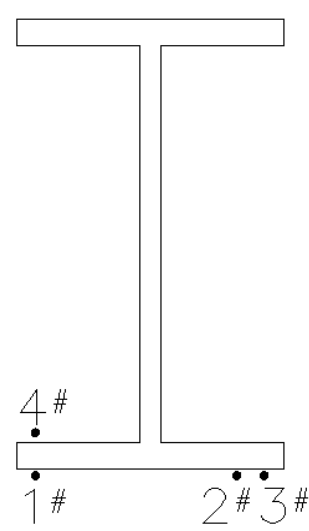

Fig. 1. 27 - 28/Даxis crane beam cross strain measuring point arrangement and number of

\section{Graphs}

Test results. Stress testing under normal production condition, the test data are as follows: the strain and stress test results of the test points are shown in Table 1, the strain of 1\# points is the minimum and the strain of $3 \#$ points is the largest.

Table 1 . crane beam stress test results

Unit : MPa

\begin{tabular}{|c|c|c|c|}
\hline Measuring point & Position & Maximum strain $(\mu \varepsilon)$ & $\begin{array}{c}\text { Maximum stress } \\
(\mathrm{MPa})\end{array}$ \\
\hline $1 \#$ & Lower flange & 227.4 & 45.5 \\
\hline $2 \#$ & Lower flange & 229.7 & 45.9 \\
\hline $3 \#$ & Lower flange & 292.6 & 58.5 \\
\hline $4 \#$ & Lower flange & 260.7 & 52.1 \\
\hline
\end{tabular}

Test data analysis. During the testing period, the strain curves of each measuring point were changed with the crane running to different positions. The strain rate at each point was basically stable, according to the trend and the changes of the curve, strain variation law of the crane girder are basically consistent with the actual state of the structure. Under the actual load of this test, the maximum stress of the test is $58.5 \mathrm{Mpa}$, and the average of the four points is $50.5 \mathrm{Mpa}$.

\section{Pillar dynamic characteristics test}

Test sensor layout. Testing the dynamic characteristics of the column mainly tested the main

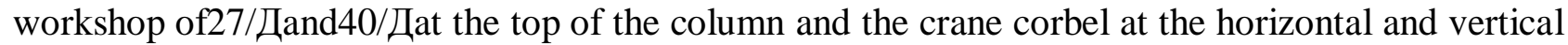
displacement amplitude. The corresponding relation between the number of the test points and the test position is shown in Table 2

Table 2. the relationship between the number of points and the test position

\begin{tabular}{|c|c|c|c|}
\hline Point number & Test position & Direction & Remarks \\
\hline D1\# & 27/ДColumn top & Horizontal & \multirow{8}{*}{$\begin{array}{l}\text { Horizontal that is } \\
\text { vertical to the } \\
\text { length of the plant, } \\
\text { longitudinal } \\
\text { direction for the } \\
\text { length of the plant. }\end{array}$} \\
\hline D2\# & 27/ДColumn top & longitudinal & \\
\hline D3\# & 27/ДCorbel & longitudinal & \\
\hline D4\# & 27/ДCorbel & Horizontal & \\
\hline D5\# & 40/ДColumn top & longitudinal & \\
\hline D6\# & 40/ДColumn top & Horizontal & \\
\hline D7\# & 40/ДCorbel & longitudinal & \\
\hline D8\# & 40/ДCorbel & Horizontal & \\
\hline
\end{tabular}


Test results and analysis. Dynamic tests are carried out in accordance with the test plan for the 27/Даnd40/Дcolumns, during testing, the maximum displacement and frequency of the measuring points are shown in table 3 . The time domain analysis of the measurement points and the typical frequency domain analysis is shown in Figure 2. According to the working status and test results of the test period, the maximum dynamic displacement of the test column are within the limits specified in the $<$ reliability evaluation criteria of industrial architecture $>($ GB50144-2008).

Table 3. test results of maximum displacement and frequency of vibration of crane girder

\begin{tabular}{|c|l|c|c|c|}
\hline \multirow{2}{*}{$\begin{array}{c}\text { Measuring } \\
\text { point }\end{array}$} & \multicolumn{1}{|c|}{ Test items } & \multicolumn{2}{|c|}{$\begin{array}{c}\text { Maximum amplitude } \\
\text { ( mm })\end{array}$} & \multicolumn{1}{|c|}{$\begin{array}{c}\text { Vibration } \\
\text { fundamental } \\
\text { frequency } \\
\text { ( Hz })\end{array}$} \\
\cline { 2 - 4 } D1\# & $\begin{array}{c}\text { 27/ДLateral displacement at the top } \\
\text { of the column }\end{array}$ & 0.66 & 1.28 & 1.20 \\
\hline D2\# & $\begin{array}{l}\text { 27/ДLateral displacement at the top } \\
\text { peak }\end{array}$ & 0.38 & 0.54 & 1.71 \\
\hline D3\# & $\begin{array}{l}\text { 27/ДThe column } \\
\text { of the corbel }\end{array}$ & 0.28 & 0.64 & 2.64 \\
\hline D4\# & $\begin{array}{l}\text { 27/ДThe lateral displacement at } \\
\text { corbel }\end{array}$ & 0.92 & 1.60 & 4.00 \\
\hline D5\# & $\begin{array}{l}\text { 40/ДLongitudinal displacement of } \\
\text { the top of the column }\end{array}$ & 0.32 & 0.56 & 1.22 \\
\hline D6\# & $\begin{array}{l}\text { 40/ДLateral displacement at the top } \\
\text { of the column }\end{array}$ & 0.62 & 1.28 & 1.17 \\
\hline D7\# & $\begin{array}{l}\text { 40/ДThe longitudinal displacement } \\
\text { of the corbel }\end{array}$ & 0.86 & 1.78 & 3.08 \\
\hline D8\# & $\begin{array}{l}\text { 40/ДThe lateral displacement at } \\
\text { corbel }\end{array}$ & 0.82 & 1.36 & 2.93 \\
\hline
\end{tabular}

Note: 1 . The peak value of the table refers to the amplitude of the relative vibration balance position. 


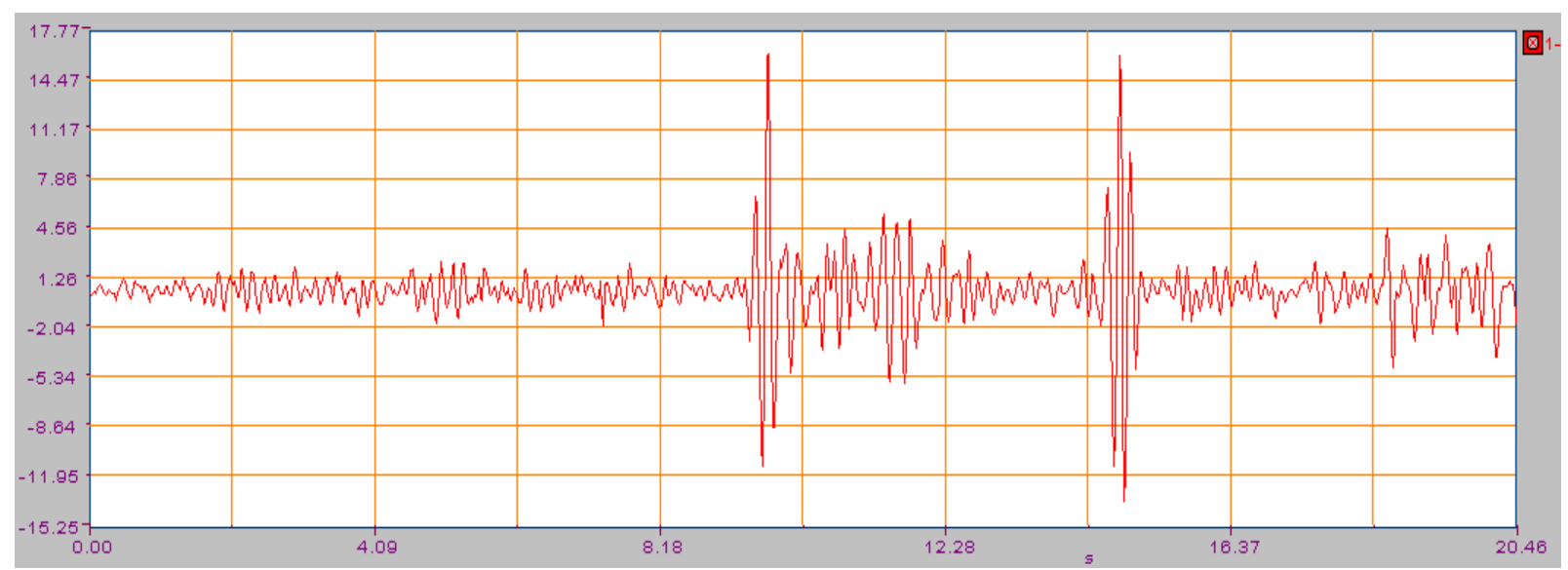

(a)time domain diagram

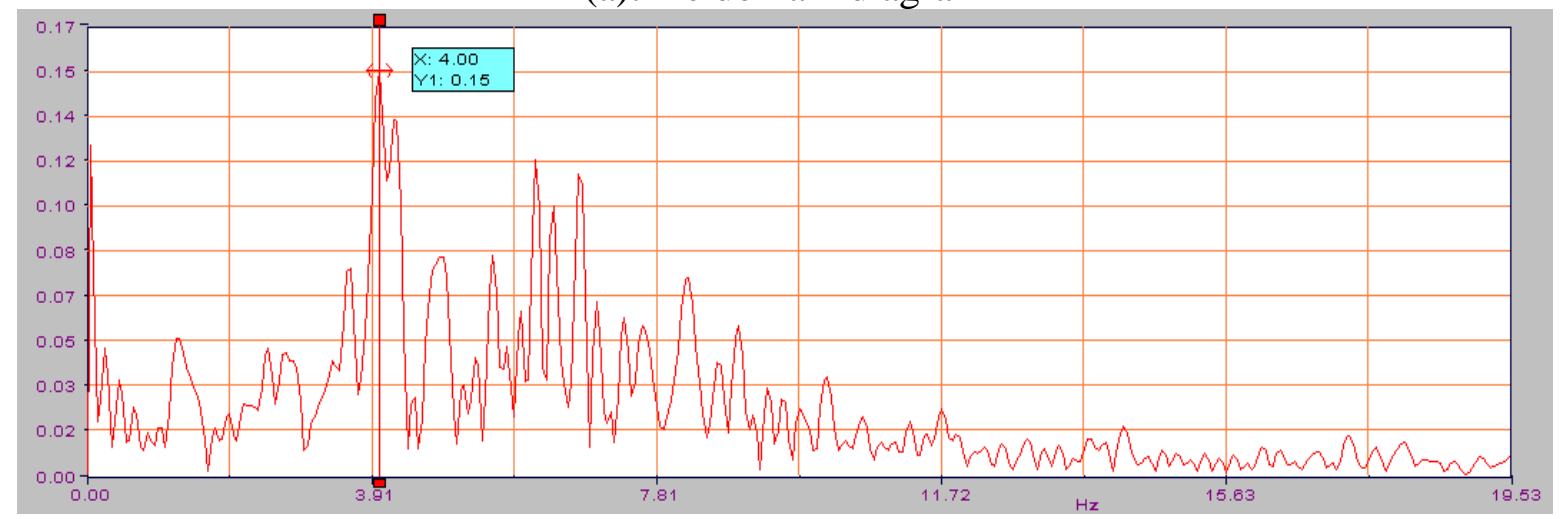

( b ) frequency domain graph

Fig.2. D4\# point analysis

\section{Conclusion}

Vibration frequency range and amplitude analysis of dynamic parameters (acceleration, velocity, and lateral displacement) of the comprehensive plant structure. The structural vibration parameters of the plant are in a state of discomfort to the human body. To improve working environment, Reduce the adverse effect of the plant shaking on the crane and other production equipment, need to strengthen the bearing capacity and durability of the column, improve the lateral stiffness of the structure of the plant, and take appropriate measures to strengthen the structure of the overall.

\section{References}

[1] GB50017-2003: Code for design of Steel structure (China Architecture and Building Press, Beijing, 2003). (in Chinese)

[2] GB/T50344-2004: Technical standards for inspection of building structure (China Architecture and Building Press, Beijing, 2004). (in Chinese)

[3] GB5009-2012 : Load code for the design of building structure (China Architecture and Building Press, Beijing, 2012). (in Chinese)

[4] GB 50144-2008: Standard for appraisal reliability of industrial building and structure (China Architecture and Building Press, Beijing, 2008). (in Chinese)

[5] CECS77:96: Technical specification for strengthening steel structures (China Architecture and Building Press, Beijing, 1996). (in Chinese)

[6] GB/T50784-2013: Technical Standard for in-situ inspection of concrete structures (China Architecture and Building Press, Beijing, 2013). (in Chinese) 